\title{
TENSILE STRENGTH OF LIQUID BRIDGES UNDER REDUCED PRESSURES
}

\author{
Received 7 April 1972
}

The strength of liquid bridges has been traditionally treated as a capillary phenomenon. In order to correlate with experimental data both a surface tension force and a reduced pressure term are necessary. The reduced pressure term is explained on the basis that the liquid beneath the concave meniscus is at a lower pressure than the surrounding atmospheric pressure. Atmospheric pressure is, therefore, held responsible for this adhesion component. Recently, O'Brien has derived the Fisher equation ${ }^{1,2}$ ) for the strength of a liquid bridge between spheres on the basis of an increased liquid surface tension term alone. An experiment to test the effect of atmospheric pressure on the strength of liquid bridges is suggested by this approach.

In order to minimize the effect of liquid evaporation, the bridge between a spherical lens and a flat plate was chosen since the strength of these bridges is independent of film thickness for small amounts of liquid ${ }^{3}$ ).

The equation for the strength of this bridge based on an increased surface tension may be derived with reference to fig. 1 . The increased liquid surface tension, $\gamma_{L}^{*}$, is given by the relation ${ }^{2}$ ),

$$
\gamma_{\mathrm{L}}^{*}=\gamma_{\mathrm{L}}+\frac{\left(\gamma_{\mathrm{SV}}-\gamma_{\mathrm{SL}}\right) A_{\mathrm{SL}}}{A_{\mathrm{LV}}}
$$

where $\left(\gamma_{\mathrm{SV}}-\gamma_{\mathrm{SL}}\right)$ represents the free energy term on wetting and $A_{\mathrm{SL}}$ and $A_{\mathrm{LV}}$ are the solid-liquid and liquid-vapor interfacial areas. The value of $\gamma^{*}$ is obtained from eq. (1) using the following geometrical approximations for low $\psi$ values,

and

$$
A_{\mathrm{LV}}=\pi^{2} s b,
$$

$$
A_{\mathrm{SL}}=2 \pi s^{2} \text {. }
$$

Substituting $\gamma \cos \theta$ from the Dupre equation for $\left(\gamma_{\mathrm{SV}}-\gamma_{\mathrm{SL}}\right)$ gives the following,

$$
\gamma^{*}=\gamma+\frac{2 s \gamma \cos \theta}{\pi b} .
$$

The work necessary to stretch the meniscus film by an amount $\delta b$ is 
equated to the increase in surface energy of the meniscus,

$$
F \delta b=\gamma^{*} \pi^{2} s \delta b,
$$

where $\pi^{2} s \delta$ is the increase in surface area.

Substituting the value of $\gamma^{*}$ from eq. (4), the following is obtained,

$$
F=\gamma \pi^{2} s+\frac{2 \gamma \cos \theta \pi s^{2}}{b} \text {. }
$$

At angles of $\psi$ of a few degrees,

$$
s^{2}=2 R b
$$

giving,

$$
F=\gamma \pi^{2} s+4 \pi R \gamma \cos \theta
$$

To test the effect of pressure on the strength of liquid bridges, a surface tension torsion balance was modified to operate by means of a small $1 \mathrm{rpm}$ electric motor. An optically ground spherical lens with a radius of curvature

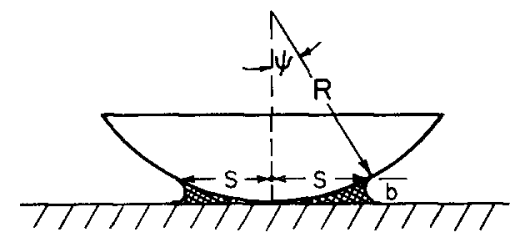

Fig. 1. Isolated capillary formed between spherical lens and flat plate.

of $17.9 \mathrm{~cm}$ and a flat glass plate were cleaned with chromate cleaning solution, and rinsed in distilled water. The force of adhesion for different volumes of degassed distilled water was measured at atmospheric pressure (742 $\mathrm{mm} \mathrm{Hg}$ ) and the results are given in table 1. At low volumes, the adhesion values remained relatively constant.

TABLE 1

Water at $24^{\circ} \mathrm{C}, P=742 \mathrm{~mm} \mathrm{Hg}$

$\begin{array}{lllllllll} & 1.13 & 0.846 & 0.564 & 0.423 & 0.282 & 0.141 & 0.100 & 0.05 \\ \text { Volume }(\mathrm{ml}) & 1.13 & 13.9 & 14.4 & 14.9 & 15.3 & 15.9 & 15.8 & 15.6 \\ \text { Force }\left(\text { dyne } \times 10^{-3} \text { ) }\right. & 13.8 & & & & & & & \end{array}$

After placing a selected volume, $0.141 \mathrm{ml}$, of water between the lens and plate, a bell jar was lowered over the apparatus and the pressure reduced by means of a mechanical pump. A mercury manometer registered the pressure in the chamber. When the selected pressure was attained, the motorized surface tension balance was turned on and the tensile force necessary to 


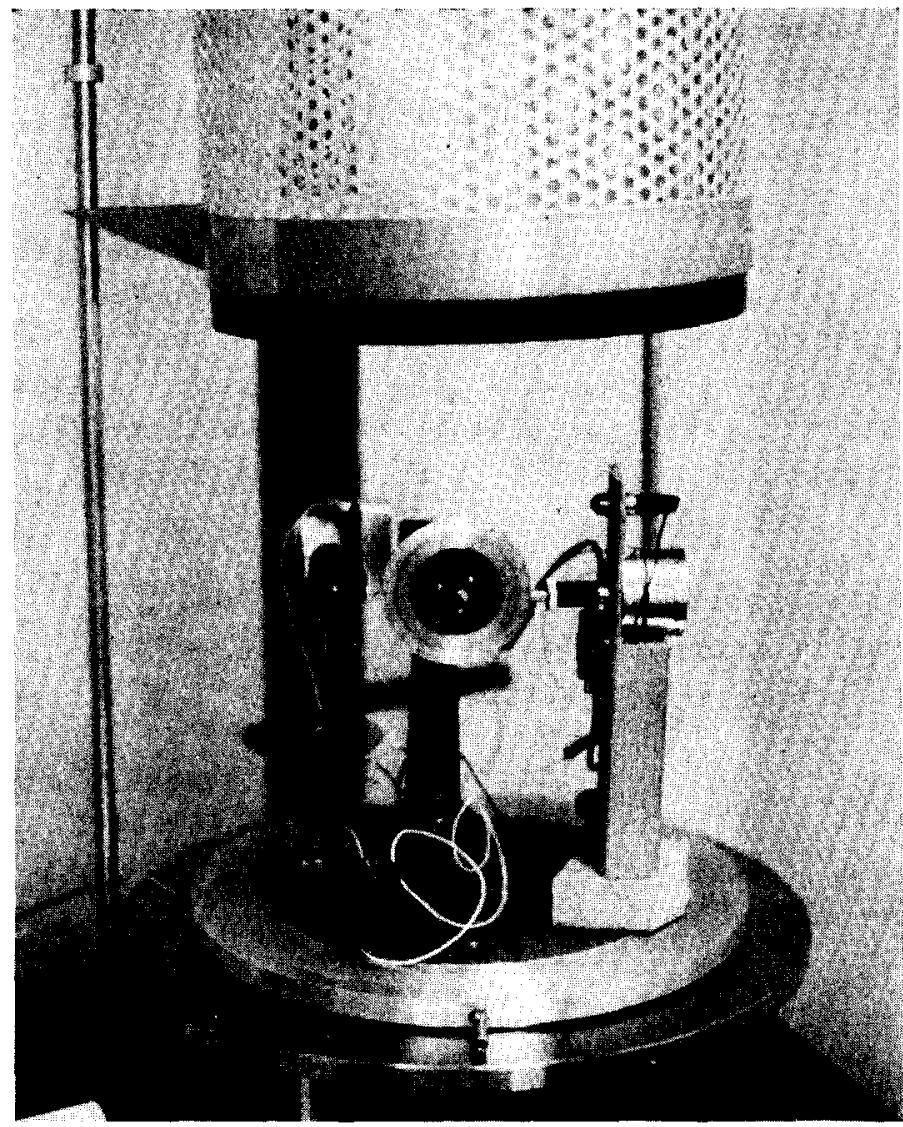

Fig. 2. Motor driven surface tension balance and vacuum chamber.

rupture the bridge was measured. Table 2 gives the results obtained. The calculated strength according to eq. (8) was $16.7 \times 10^{3}$ dyne for $\psi=4^{\circ}$ and $\theta=10^{\circ}$. The values of adhesive force under reduced pressure were all lower but were not reduced by the pressure changes. These results indicate that the reductions in atmospheric pressure had an insignificant effect on the liquid bridge adhesion and therefore give support to the theory that an

TABLE 2

Water at $24^{\circ} \mathrm{C}, V=0.141 \mathrm{ml}$

\begin{tabular}{lccccccc}
\hline Pressure $(\mathrm{mm} \mathrm{Hg})$ & 742 & 600 & 500 & 400 & 300 & 200 & 100 \\
Force $\left(\right.$ dyne $\left.\times 10^{-3}\right)$ & 15.8 & 15.9 & 15.9 & 15.9 & 15.9 & 15.9 & 15.9 \\
\hline
\end{tabular}


increased surface tension is responsible for the strength of liquid bridges in small capillaries.

The capillary equation derived by Young and Laplace in 1805 giving the difference in pressure across a curved surface relates only to bubbles ${ }^{4}$ ). Its application of liquids with curved surfaces is erroneous. The adhesion of solids by liquid bridges has its origin in the liquid-solid interaction. The desorption of vacancies from the liquid-solid interface results in a higher concentration and greater average intermolecular distance at the liquidvapor interface. This in turn leads to higher intermolecular attraction or surface tension. The desorption of vacancies from the liquid-solid interface has been experimentally verified by Rayleigh and Brillouin light scattering ${ }^{5}$ ).

Acknowledgement is due to Professor Major Ash for the use of his high volume vacuum apparatus and to the National Institute of Dental Research Grant \# DE 03480, U.S.P.H. for financial support.

\section{W. J. O'BRIEN and ChIN UY Yu}

School of Dentistry, University of Michigan, Ann Arbor, Michigan 48104, U.S.A.

\section{References}

1) W. J. O'Brien, Surface Sci. 19 (1970) 387

2) W. J. O'Brien, Surface Sci. 25 (1971) 298.

3) J. S. McFarlane and D. Tabor, Proc. Roy. Soc. (London) A 202 (1950) 224.

4) A. W. Adamson, Physical Chemistry of Surface (Interscience, New York, 1960) p. 4.

5) A. Olivei, Optik 32 (1970) 218. 